\title{
Small sagittal vertical axis accompanied with lumbar hyperlordosis as a risk factor for developing postoperative cervical kyphosis after expansive open-door laminoplasty
}

\author{
Yuji Matsuoka, MD, Hidekazu Suzuki, MD, PhD, Kenji Endo, MD, PhD, Yasunobu Sawaji, PhD, \\ Kazuma Murata, MD, PhD, Hirosuke Nishimura, MD, PhD, Hidetoshi Tanaka, MD, PhD, and \\ Kengo Yamamoto, MD, PhD
}

Department of Orthopedic Surgery, Tokyo Medical University, Tokyo, Japan

\begin{abstract}
OBJECTIVE Preoperative positive cervical sagittal imbalance and global sagittal imbalance are risk factors for postoperative cervical kyphosis after expansive open-door cervical laminoplasty (ELAP). The purpose of this study was to investigate the relationship between the incidence of postoperative cervical kyphosis after ELAP and the preoperative global sagittal spinal alignment in patients with cervical spondylotic myelopathy (CSM) without spinal sagittal imbalance.

METHODS Among 84 consecutive patients who underwent ELAP for CSM at the authors' hospital, 43 patients without preoperative cervical kyphosis ( $22-7$ angle $\geq 0^{\circ}$ ) and spinal sagittal imbalance (C2-7 sagittal vertical axis [SVA] $\leq 80$ $\mathrm{mm}$ and C-7 SVA $\leq 95 \mathrm{~mm}$ ) were included in the study. The global spinal sagittal parameters were measured on lateral whole-spine standing radiographs preoperatively and at 1 year postoperatively. The difference in preoperative global sagittal spinal alignment between the postoperative cervical lordosis group and the cervical kyphosis group was analyzed.
\end{abstract}

RESULTS The incidence of postoperative cervical kyphosis after ELAP was $25.6 \%$ ( 11 of 43 cases). Thirty-two patients (16 men and 16 women; mean age $67.7 \pm 12.0$ years) had lordosis, and 11 ( 7 men and 4 women; mean age $67.2 \pm 9.6$ years) had kyphosis. The preoperative C-7 SVA and pelvic incidence minus lumbar lordosis (PI-LL) in the kyphosis group were significantly smaller than those in the lordosis group $(p<0.05)$. The smaller C-7 SVA accompanied by a small PI-LL, the "truncal negative offset," led to postoperative cervical kyphosis due to posterior structural weakening by ELAP.

CONCLUSIONS In patients with CSM without preoperative cervical and global spinal sagittal imbalance, a small SVA accompanied by lumbar hyperlordosis is the characteristic alignment leading to postoperative cervical kyphosis after ELAP.

https://thejns.org/doi/abs/10.3171/2017.12.SPINE17557

KEYWORDS sagittal spinal alignment; cervical laminoplasty; cervical kyphosis; lumbar

$\mathrm{E}$ XPANSIVE open-door cervical laminoplasty (ELAP) has been widely performed for the treatment of patients with multilevel cervical spondylotic myelopathy (CSM). ELAP is thought to be an operation that preserves posterior elements (e.g., the ligamentous tension band) ${ }^{12}$ by a posterior approach. Cervical laminoplasty has several advantages in avoiding problems associated with laminectomy, including postoperative segmental instability, kyphosis, perineural adhesions, and late neurological deterioration. ${ }^{11}$ The theoretical advantage of laminoplasty is that it can preserve stability of the cervical spine, preventing postoperative kyphosis that can occur after laminectomy. Compared with laminectomy, the incidence of postoperative kyphosis is lower. ${ }^{11}$

Postoperative cervical kyphosis can occur after ELAP even if the patient had sufficient preoperative cervical lordosis. ${ }^{1,19}$ Previous studies have shown a younger age at the time of surgery, laminectomy of 4 or more levels, surgery

ABBREVIATIONS CL = cervical lordosis; $C S M=$ cervical spondylotic myelopathy; $\mathrm{DISH}=$ diffuse idiopathic skeletal hyperostosis; ELAP = expansive open-door cervical laminoplasty; LL = lumbar lordosis; OPLL = ossification of the posterior longitudinal ligament; PI = pelvic incidence; PT = pelvic tilt; SVA = sagittal vertical axis; $\mathrm{TK}=$ thoracic kyphosis.

SUBMITTED June 21, 2017. ACCEPTED December 29, 2017.

INCLUDE WHEN CITING Published online May 25, 2018; DOI: 10.3171/2017.12.SPINE17557. 
involving the C-2 lamina, performance of facetectomies, and increased preoperative range of motion as predictive factors. ${ }^{4,6}$ With the recent work investigating the outcomes after laminoplasty, positive global sagittal imbalance preoperatively was found to be associated with poor postoperative clinical outcomes, ${ }^{15}$ suggesting that cervical and global spinal sagittal balance should be taken into consideration when deciding whether to perform an ELAP. Because a previous study mentioned that positive cervical imbalance is a risk factor for postoperative cervical kyphosis,$^{15}$ the indication of ELAP would be controversial for patients who have severe positive cervical imbalance preoperatively. In this study, we therefore focused on patients who do not have positive cervical and global sagittal imbalance. The purpose of this study was to investigate the relationship between the incidence of postoperative cervical kyphosis after ELAP and the preoperative total spinal sagittal alignment in selected patients whose cervical and global spinal sagittal alignment were not imbalanced.

\section{Methods}

Between January 2011 and December 2015, 138 consecutive patients underwent cervical operations for CSM; 84 consecutive patients underwent ELAP at our hospital (anterior decompression and fixation in 47 cases, posterior decompression with instrumentation in 5 cases, and anterior and posterior in 2 cases). Among them, 43 patients without preoperative cervical kyphosis $\left(\mathrm{C} 2-7\right.$ angle $\geq 0^{\circ}$ ) and without spinal sagittal imbalance according to cervical spine deformity classification ${ }^{2}$ and adult spinal deformity ${ }^{17}(\mathrm{C} 2-7 \mathrm{SVA} \leq 80 \mathrm{~mm}$; C-7 SVA $\leq 95 \mathrm{~mm}$ ) were included. There were 23 male patients and 20 female patients, with a mean age of $67.5 \pm 13.7$ years. The patients' preoperative measurements are summarized in Table 1. All patients provided written informed consent after explanation of the experimental protocol. This study was approved by the institutional review board of our institution. Patients with myelopathy caused by cervical disc herniation or cervical ossification of the posterior longitudinal ligament (OPLL), diffuse idiopathic skeletal hyperostosis (DISH), ELAP with posterior or anterior fusion, sigmoid curve of the cervical spine, occiput-C2 deformity, a history of previous cervical spine surgery, Parkinson disease, neurological disease, or patients who could not stand up without assistance were excluded.

The following parameters were measured on lateral whole-spine standing radiographs preoperatively and at 1 year postoperatively: the total distance from the plumb line of the pedicle center of the $\mathrm{C}-2$ vertebra to the posterior superior corner of the C-7 vertebra (C2-7 sagittal vertical axis [SVA]); cervical lordosis (CL) assessed by the $\mathrm{C} 2-7 \mathrm{Cobb}$ angle (defined as the angle from the lower endplate of C-2 to the lower endplate of C-7); the angle between the $\mathrm{T}-1$ upper endplate and the horizontal plane (T-1 slope); the angle between the T-4 upper edge and T-12 lower edge (thoracic kyphosis [TK]); the distance from the C-7 plumb line to the sacral posterior angle (C-7 SVA); the angle from the upper endplate of L-1 to the upper endplate of the sacrum (lumbar lordosis [LL]); the angle between the sacral plate and the horizontal plane (sacral slope);
TABLE 1. Preoperative total spinal sagittal alignment

\begin{tabular}{lc}
\hline \multicolumn{1}{c}{ Parameter } & Mean \pm SD \\
\hline $\mathrm{C} 2-7$ SVA $(\mathrm{mm})$ & $14.6 \pm 10.4$ \\
\hline $\mathrm{CL}\left({ }^{\circ}\right)$ & $27.6 \pm 7.3$ \\
\hline $\mathrm{T}-1$ slope $\left(^{\circ}\right)$ & $31.8 \pm 12.6$ \\
\hline $\mathrm{C}-7$ SVA $(\mathrm{mm})$ & $43.8 \pm 13.2$ \\
\hline $\mathrm{TK}\left({ }^{\circ}\right)$ & $46.8 \pm 12.2$ \\
\hline $\mathrm{LL}\left(^{\circ}\right)$ & $15.8 \pm 6.5$ \\
\hline $\mathrm{PT}\left({ }^{\circ}\right)$ & $24.2 \pm 11.0$ \\
\hline $\mathrm{PI}\left({ }^{\circ}\right)$ & $23.1 \pm 49.9$ \\
\hline $\mathrm{PI}-\mathrm{LL}\left({ }^{\circ}\right)$ & $3.0 \pm 11.1$ \\
\hline
\end{tabular}

the angle between the line connecting the midpoint of the sacral plate to the axis of the femoral head and the gravity line (pelvic tilt [PT]); and the angle between the perpendicular to the sacral plate at its midpoint and the line connecting the point to the middle axis of the femoral head (pelvic incidence $[\mathrm{PI}])^{2}$ (Fig. 1). Whole-spine anteroposterior and lateral radiographs were obtained using the digital slot-scanning radiography mode of the Sonialvision Safire fluoroscopy system (Shimadzu Corp.). An alignment of the $\mathrm{C} 2-7 \mathrm{Cobb}$ angle of $0^{\circ}$ or more was defined as lordosis, and an alignment of the $\mathrm{C} 2-7 \mathrm{Cobb}$ angle less than $0^{\circ}$ was defined as kyphosis. ${ }^{10}$ Based on the data obtained at 1 year after ELAP, the patients were divided into 2 groups as follows: the lordosis group and kyphosis group.

The clinical outcome was evaluated by the recovery rate according to the Japanese Orthopaedic Association scoring system for cervical myelopathy. ${ }^{5}$ Values are expressed as the mean \pm standard deviation. Statistical analyses were performed using the JMP software package (version 10.0, SAS Institute Inc.). The Shapiro-Wilk W test was used for the goodness-of-fit to the normal distribution. The Student t-test was used to determine intergroup differences between the lordosis and kyphosis groups to evaluate the outcome measures of sagittal spinal parameters. The correlations between the variables of spinopelvic parameters were examined using Pearson's rank correlation coefficient. Stepwise single regression analysis was used to detect the postoperative CL by the preoperative spinal sagittal parameters. A $p$ value $<0.05$ was considered to indicate a statistically significant difference.

\section{Results}

Cervical kyphosis was present in 11 of 43 patients (25.6\%) 1 year after ELAP. The lordosis group comprised 32 patients ( 16 men and 16 women; mean age $67.7 \pm 12.0$ years). The kyphosis group consisted of 11 patients (7 men and 4 women; mean age 67.2 \pm 9.6 years) (Table 2 ). Regarding preoperative total sagittal spinal alignment of the kyphosis group, the C-7 SVA was significantly smaller than that of the lordosis group $(\mathrm{p}<0.05)$ (Table 2). The PILL in the kyphosis group was significantly smaller than that of the lordosis group preoperatively and postoperatively (Table 3). The preoperative C-7 SVA and PI-LL had a positive correlation with postoperative CL (Table 4 and Fig. 2). The recovery rate according to the Japanese Or- 


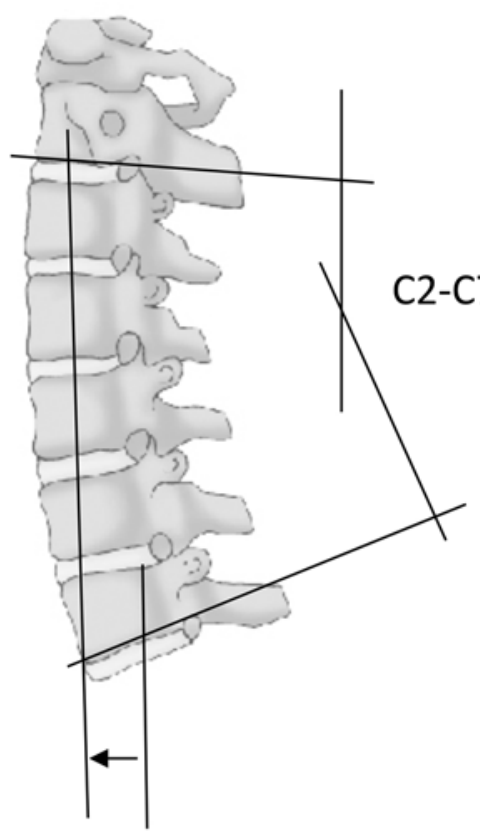

C2-C7 SVA
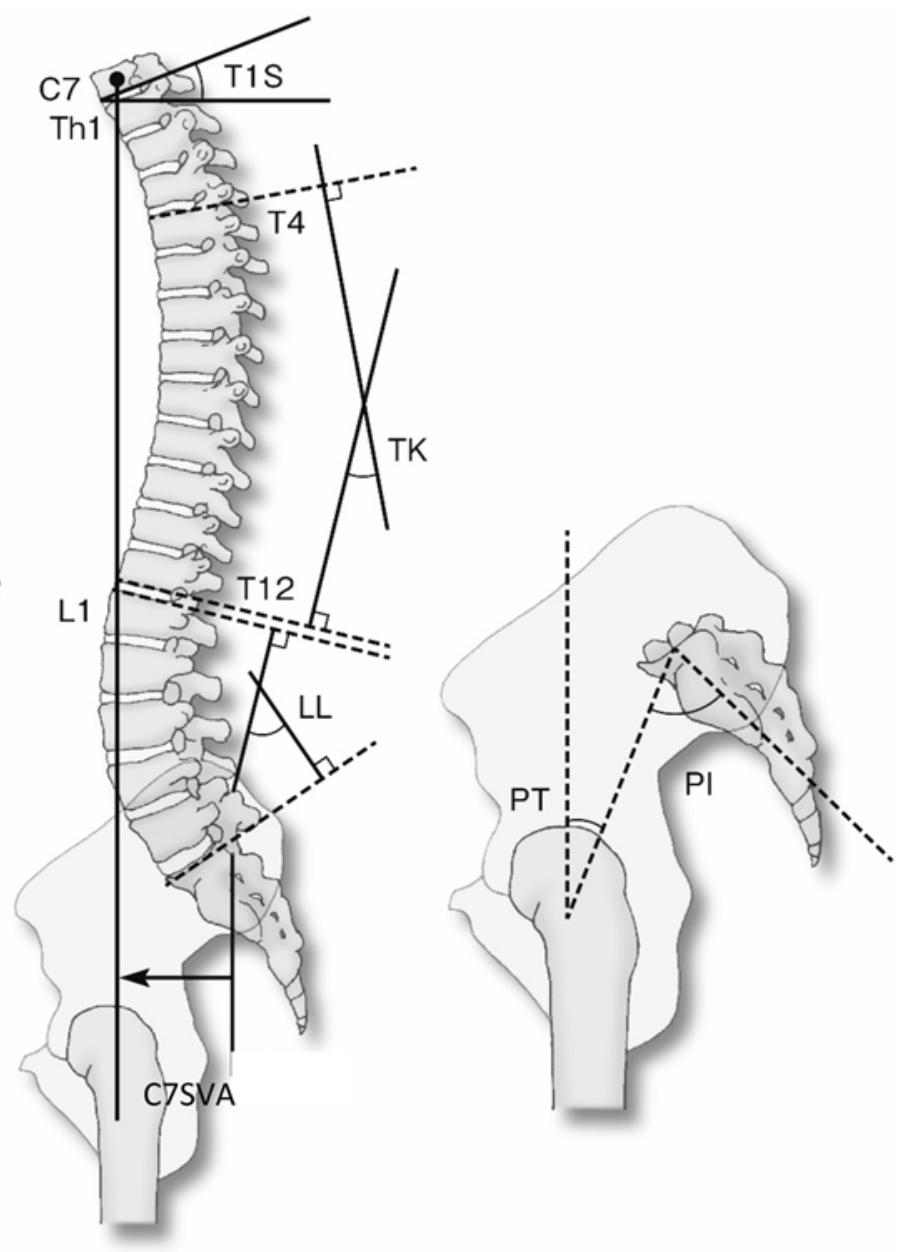

FIG. 1. Spinal and pelvic alignment measurements. T1S = T-1 slope. Copyright Kenji Endo. Published with permission.

thopaedic Association for cervical myelopathy score was $43.7 \% \pm 13.2 \%$ in the lordosis group and $38.2 \% \pm 17.0 \%$ in the kyphosis group.

\section{Discussion}

It is well known that cervical malalignment affects

TABLE 2. Patient characteristics and preoperative parameters

\begin{tabular}{lccc}
\hline \multicolumn{1}{c}{ Parameter } & Lordosis Group & Kyphosis Group & p Value \\
\hline Age $(\mathrm{yrs})$ & $67.7 \pm 12.0$ & $67.2 \pm 9.6$ & 0.91 \\
\hline Sex $(\mathrm{M} / \mathrm{F})$ & $16 / 16$ & $7 / 4$ & 0.50 \\
\hline $\mathrm{C} 2-7$ SVA $(\mathrm{mm})$ & $23.8 \pm 11.9$ & $25.0 \pm 8.7$ & 0.75 \\
\hline $\mathrm{CL}\left({ }^{\circ}\right)$ & $16.6 \pm 10.3$ & $10.1 \pm 8.9$ & 0.05 \\
\hline $\mathrm{T}-1$ slope $\left({ }^{\circ}\right)$ & $28.4 \pm 7.8$ & $25.3 \pm 5.8$ & 0.23 \\
\hline $\mathrm{C}-7 \mathrm{SVA}(\mathrm{mm})$ & $33.7 \pm 52.7$ & $-5.7 \pm 27.3$ & 0.02 \\
\hline $\mathrm{TK}\left({ }^{\circ}\right)$ & $31.2 \pm 13.1$ & $33 \pm 11.9$ & 0.70 \\
\hline $\mathrm{LL}\left({ }^{\circ}\right)$ & $40.5 \pm 10.1$ & $49.5 \pm 11.8$ & 0.33 \\
\hline $\mathrm{PT}\left({ }^{\circ}\right)$ & $16.4 \pm 6.9$ & $13.3 \pm 4.4$ & 0.09 \\
\hline $\mathrm{PI}\left({ }^{\circ}\right)$ & $48.2 \pm 13.0$ & $38.9 \pm 3.7$ & 0.17 \\
\hline $\mathrm{PI}-\mathrm{LL}\left({ }^{\circ}\right)$ & $5.4 \pm 10.9$ & $-4.5 \pm 8.8$ & 0.01 \\
\hline
\end{tabular}

the incidence of cervical myelopathy. ${ }^{14}$ Having sufficient preoperative cervical lordosis is a prerequisite for laminoplasty, ${ }^{18}$ and maintaining postoperative lordosis is important for spinal cord decompression. ${ }^{19}$ Postoperative cervical kyphosis is the most prevalent cervical spinal deformity secondary to cervical posterior decompression surgery. ${ }^{16}$ However, despite having sufficient preoperative lordosis, cervical laminoplasty often diminishes the lordosis. ${ }^{1}$ For example, Lee et al. stated that the cervical lordosis

\section{TABLE 3. Postoperative parameters}

\begin{tabular}{lccc}
\hline \multicolumn{1}{c}{ Parameter } & Lordosis Group & Kyphosis Group & p Value \\
\hline C2-7 SVA $(\mathrm{mm})$ & $24.6 \pm 14.4$ & $36.1 \pm 13.4$ & 0.02 \\
\hline $\mathrm{CL}\left({ }^{\circ}\right)$ & $14.5 \pm 11.1$ & $-7.6 \pm 5.2$ & $<0.0001$ \\
\hline T-1 slope $\left(^{\circ}\right)$ & $26.0 \pm 10.1$ & $27.8 \pm 7.7$ & 0.54 \\
\hline C-7 SVA $(\mathrm{mm})$ & $28.4 \pm 45.7$ & $-2.8 \pm 24.7$ & 0.04 \\
\hline $\mathrm{TK}\left({ }^{\circ}\right)$ & $27.8 \pm 14.9$ & $33.9 \pm 10.8$ & 0.16 \\
\hline $\mathrm{LL}\left({ }^{\circ}\right)$ & $41.4 \pm 13.0$ & $46.4 \pm 12.6$ & 0.16 \\
\hline $\mathrm{PT}\left({ }^{\circ}\right)$ & $15.9 \pm 7.7$ & $12.5 \pm 5.4$ & 0.17 \\
\hline $\mathrm{PI}\left({ }^{\circ}\right)$ & $48.2 \pm 2.1$ & $38.9 \pm 3.9$ & 0.04 \\
\hline $\mathrm{PI}-\mathrm{LL}\left({ }^{\circ}\right)$ & $5.0 \pm 9.2$ & $-3.5 \pm 6.0$ & 0.01 \\
\hline
\end{tabular}


TABLE 4. Correlations between the postoperative $\mathrm{C} 2-7$ angle and preoperative alignment parameters

\begin{tabular}{lccccccccc}
\hline & C2-7 SVA & C-7 SVA & CL & T-1 slope & TK & LL & PT & PI & PI-LL \\
\hline Correlation & -0.23 & 0.42 & 0.65 & 0.36 & 0.10 & -0.14 & 0.16 & 0.15 & 0.35 \\
\hline p value & 0.13 & $<0.01$ & $<0.01$ & 0.02 & 0.51 & 0.36 & 0.30 & 0.32 & 0.02 \\
\hline
\end{tabular}

decreased in 35 of 50 cases (70\%) after ELAP. ${ }^{9}$ Sakai et al. explored factors associated with postoperative kyphosis and found that preoperative positive cervical sagittal imbalance was a risk factor for cervical kyphotic deformity after laminoplasty. ${ }^{15} \mathrm{Kim}$ et al. also reported that uncompensated cervical sagittal spinal balance and the weight of the head will act as a continuous kyphotic force for cervical sagittal balance and patients with high T-1 slope and insufficient lordosis are subjected to a kyphotic force in the cervical spine. ${ }^{8}$ On the other hand, other studies have shown that postoperative kyphosis did not occur frequently in patients with a higher T-1 slope. ${ }^{3,7} \mathrm{Kim}$ et al. reported that the incidence of postoperative cervical kyphosis after ELAP was $25.7 \%$ (9 of 35 cases) with a high T-1 slope and $20.7 \%$ (6 of 29 cases) with a low T-1 slope. ${ }^{7}$ The predictors of postoperative kyphosis have been unclear and a matter of debate in past studies. We hypothesized that this controversy may have been caused by analyzing only cervical regional alignment ${ }^{3,7,8}$ and that the evaluation of the "global sagittal balance" must be included for the analysis. Recently, Oshima et al. ${ }^{13}$ suggested that global sagittal balance and cervical regional alignment should be considered in evaluating clinical outcomes for patients undergoing ELAP.

In our current study, the kyphosis group exhibited a statistically significant smaller C-7 SVA preoperatively. The PI-LL was statistically small in the kyphosis group $\left(-4.5^{\circ}\right.$ $\pm 8.8^{\circ}$ ). We concluded that the characteristic preoperative distribution of sagittal spinal alignment in the kyphosis group was small CL, C-7 SVA, and PI-LL. However, the cutoff value of cervical lordosis for preventing postoperative cervical kyphosis is difficult to determine because cervical lordosis is affected by the global sagittal spinal alignment. Previously, the clinical significance of negative sagittal imbalance has not been clearly revealed. Our re- sults suggest that patients who have a preoperative large LL with a small PI and truncal negative offset, so-called reciprocal change, will develop postoperative cervical kyphosis after the posterior structure is weakened by ELAP. From previous findings $\mathrm{s}^{7,8,15}$ and our results, we propose that there could be 2 types of preoperative characteristic alignments leading to postoperative kyphosis after ELAP (Fig. $3)$. When performing ELAP in patients with normal spinal sagittal balance, the truncal negative offset associated with hyperlordosis (small PI-LL) is an important factor for predicting postoperative cervical kyphosis. Therefore, we may need to consider an additional procedure for these patients to avoid postoperative cervical kyphosis by performing either anterior or posterior fusion during ELAP.

This study has some limitations. The number of patients was relatively small due to the strict inclusion criteria, which excluded patients with spinal sagittal imbalance, OPLL, and DISH. If patients with OPLL and DISH were included, the rate of postoperative kyphosis might have been decreased further. In a future study, we should add more patients and conduct a study with longer follow-up.

\section{Conclusions}

In patients with CSM without cervical and global spinal sagittal imbalance, a small SVA with lumbar hyperlordosis is the characteristic alignment leading to postoperative cervical kyphosis after ELAP.

\section{Acknowledgments}

We are indebted to the Department of International Medical Communications of Tokyo Medical University for assistance with English language editing. We also thank Ms. Yuri Amamizu of the Department of Orthopedic Surgery for assistance with preparing the initial English manuscript. No benefits in any form have been
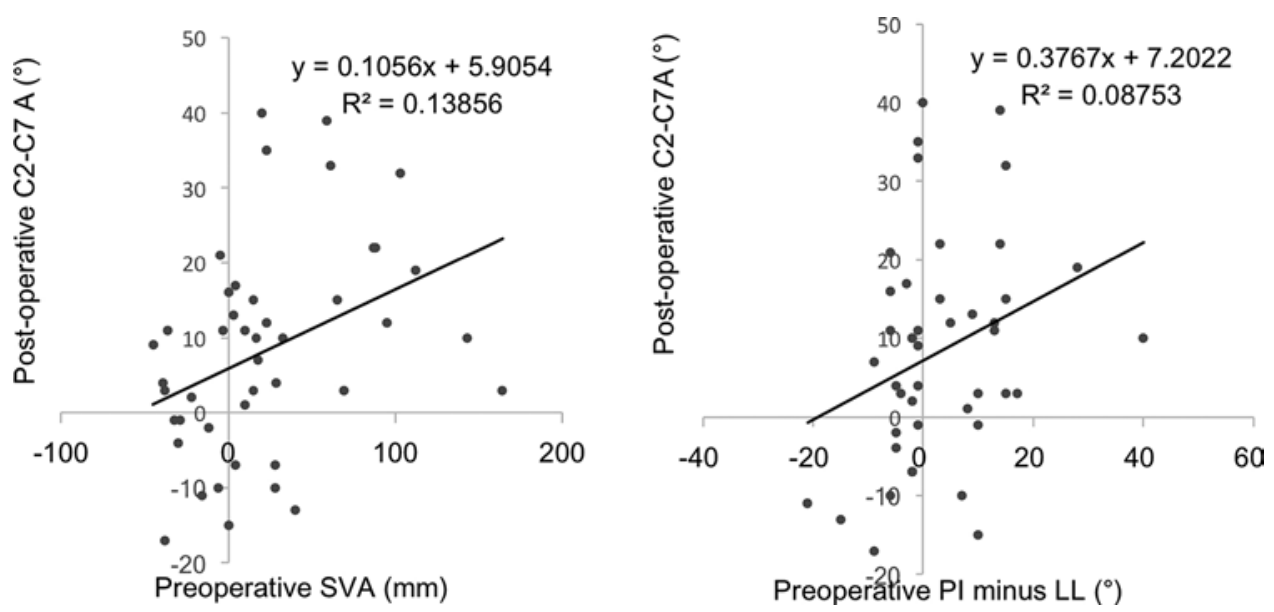

FIG. 2. Correlations between postoperative C2-7 angle (A) and preoperative SVA (left) and preoperative PI-LL (right). 


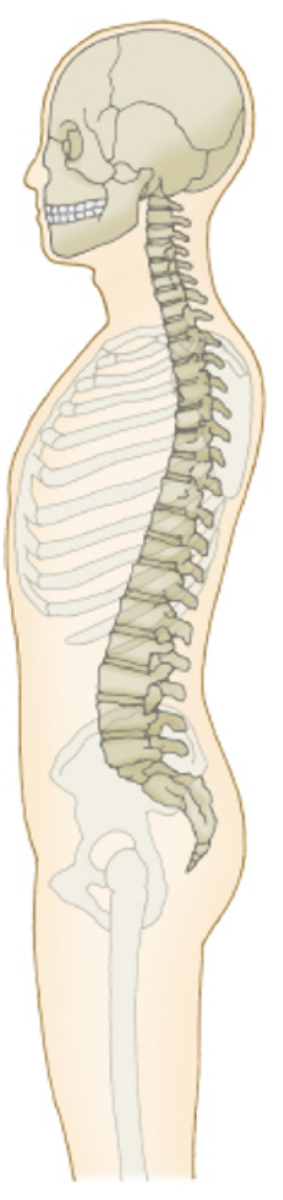

A

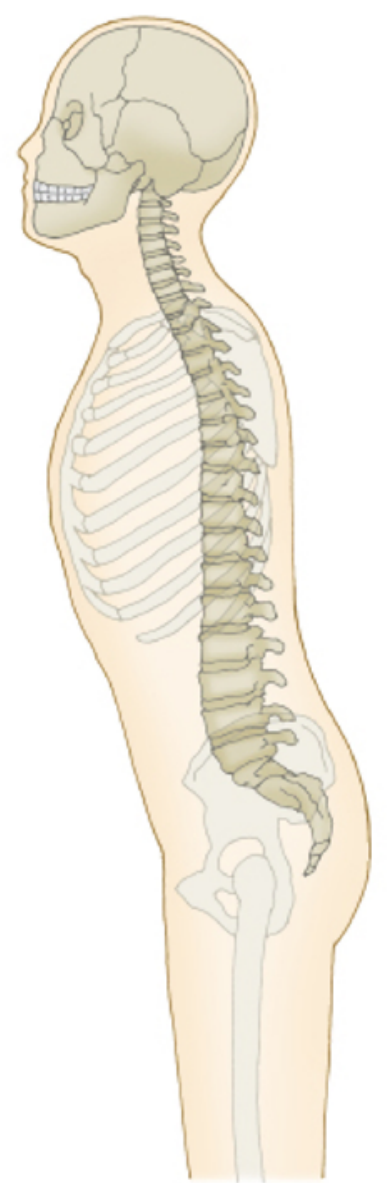

B

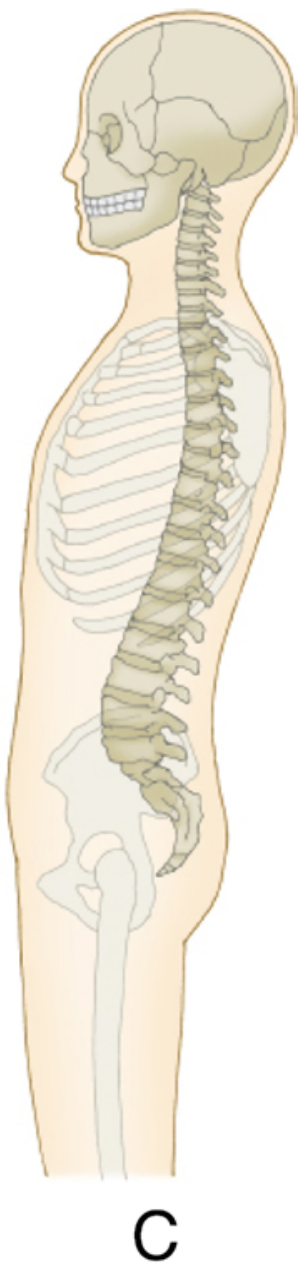

FIG. 3. A: Standard spinal sagittal balance. B: Positive C-7 SVA imbalance. C: Negative C-7 SVA imbalance. Copyright Kenji Endo. Published with permission. Figure is available in color online only.

received or will be received from any commercial party associated directly or indirectly with this study.

\section{References}

1. Aita I, Wadano Y, Yabuki T: Curvature and range of motion of the cervical spine after laminaplasty. J Bone Joint Surg Am 82-A:1743-1748, 2000

2. Ames CP, Blondel B, Scheer JK, Schwab FJ, Le Huec J-C, Massicotte EM, et al: Cervical radiographical alignment: comprehensive assessment techniques and potential importance in cervical myelopathy. Spine (Phila Pa 1976) 38 (22 Suppl 1):S149-S160, 2013

3. Cho JH, Ha JK, Kim DG, Song KY, Kim YT, Hwang CJ, et al: Does preoperative T1 slope affect radiological and functional outcomes after cervical laminoplasty? Spine (Phila Pa 1976) 39:E1575-E1581, 2014

4. Guigui P, Benoist M, Deburge A: Spinal deformity and instability after multilevel cervical laminectomy for spondylotic myelopathy. Spine (Phila Pa 1976) 23:440-447, 1998

5. Hirabayashi K, Miyakawa J, Satomi K, Maruyama T, Wakano K: Operative results and postoperative progression of ossification among patients with ossification of cervical posterior longitudinal ligament. Spine (Phila Pa 1976) 6:354-364, 1981

6. Katsumi Y,Honma T, Nakamura T: Analysis of cervical instability resulting from laminectomies for removal of spinal cord tumor. Spine (Phila Pa 1976) 14:1171-1176, 1989

7. Kim B, Yoon DH, Ha Y, Yi S, Shin DA, Lee CK, et al: Relationship between T1 slope and loss of lordosis after laminoplasty in patients with cervical ossification of the posterior longitudinal ligament. Spine J 16:219-225, 2016

8. Kim TH, Lee SY, Kim YC, Park MS, Kim SW: T1 slope as a predictor of kyphotic alignment change after laminoplasty in patients with cervical myelopathy. Spine (Phila Pa 1976) 38:E992-E997, 2013

9. Lee W, Choo YS, Kim YB, Chung J: Neurological deterioration after decompressive suboccipital craniectomy in a patient with a brainstem-compressing thrombosed giant aneurysm of the vertebral artery. J Cerebrovasc Endovasc Neurosurg 18:115-119, 2016

10. Machino M, Yukawa Y, Hida T, Ito K, Nakashima H, Kanbara S, et al: Cervical alignment and range of motion after laminoplasty: radiographical data from more than 500 cases with cervical spondylotic myelopathy and a review of the literature. Spine (Phila Pa 1976) 37:E1243-E1250, 2012

11. Matsunaga S, Sakou T, Nakanisi K: Analysis of the cervical spine alignment following laminoplasty and laminectomy. Spinal Cord 37:20-24, 1999

12. Motosuneya T, Maruyama T, Yamada H, Tsuzuki N, Sakai $\mathrm{H}$ : Long-term results of tension-band laminoplasty for 
cervical stenotic myelopathy: a ten-year follow-up. J Bone Joint Surg Br 93:68-72, 2011

13. Oshima Y, Takeshita K, Taniguchi Y, Matsubayashi Y, Doi $\mathrm{T}$, Ohya J, et al: Effect of preoperative sagittal balance on cervical laminoplasty outcomes. Spine (Phila Pa 1976) 41:E1265-E1270, 2016

14. Ross JR, Nepple JJ, Philippon MJ, Kelly BT, Larson CM, Bedi A: Effect of changes in pelvic tilt on range of motion to impingement and radiographic parameters of acetabular morphologic characteristics. Am J Sports Med 42:2402-2409, 2014

15. Sakai K, Yoshii T, Hirai T, Arai Y, Torigoe I, Tomori M, et al: Cervical sagittal imbalance is a predictor of kyphotic deformity after laminoplasty in cervical spondylotic myelopathy patients without preoperative kyphotic alignment. Spine (Phila Pa 1976) 41:299-305, 2016

16. Schwab F, Ungar B, Blondel B, Buchowski J, Coe J, Deinlein D, et al: Scoliosis Research Society-Schwab adult spinal deformity classification: a validation study. Spine (Phila Pa 1976) 37:1077-1082, 2012

17. Schwab FJ, Blondel B, Bess S, Hostin R, Shaffrey CI, Smith JS, et al: Radiographical spinopelvic parameters and disability in the setting of adult spinal deformity: a prospective multicenter analysis. Spine (Phila Pa 1976) 38:E803-E812, 2013

18. Suda K, Abumi K, Ito M, Shono Y, Kaneda K, Fujiya M: Local kyphosis reduces surgical outcomes of expansive opendoor laminoplasty for cervical spondylotic myelopathy. Spine (Phila Pa 1976) 28:1258-1262, 2003
19. Suk KS, Kim KT, Lee JH, Lee SH, Lim YJ, Kim JS: Sagittal alignment of the cervical spine after the laminoplasty. Spine (Phila Pa 1976) 32:E656-E660, 2007

\section{Disclosures}

The authors report no conflict of interest concerning the materials or methods used in this study or the findings specified in this paper.

\section{Author Contributions}

Conception and design: Endo, Matsuoka, Suzuki, Tanaka, Yamamoto. Acquisition of data: Endo, Matsuoka, Suzuki, Murata, Nishimura, Tanaka. Analysis and interpretation of data: Endo, Matsuoka, Suzuki, Sawaji, Murata, Nishimura. Drafting the article: Endo, Sawaji. Critically revising the article: Endo, Matsuoka, Sawaji. Reviewed submitted version of manuscript: Endo, Matsuoka, Suzuki, Sawaji, Yamamoto. Approved the final version of the manuscript on behalf of all authors: Endo. Statistical analysis: Endo, Matsuoka, Suzuki, Sawaji. Administrative/technical/ material support: Endo. Study supervision: Endo, Suzuki, Sawaji, Yamamoto.

\section{Correspondence}

Kenji Endo: Tokyo Medical University, Tokyo, Japan. kendo@ tokyo-med.ac.jp. 